\title{
SOME LIFE HISTORY NOTES ON THE BLACK WIDOW SPIDER LATRODECTUS MACTANS. ${ }^{1}$
}

\author{
By PhIL Rau.
}

St. Louis, Mo.

This spider in livery of shining black decorated with bright red blotches, and called by Comstock the black widow spider, is often found in the vicinity of St. Louis under rocks and debris in sunny pastures. One specimen, with its round, white egg-case, was taken from her web high up in a corner of a barn on June 23, 1922.

In captivity she made four more of these ego-cases, on June 24, July 12, August 4 and August 15 respectively. After the making of each, her abdomen was shrunken to about half its former size, but it soon returned to normal proportions. Despite the fact that this individual had not access to the male, after its capture, the eggs in all five cocoons were fertile; this circumstance shows that it is not necessary for mating to precede each case of oviposition.

All the young in each cocoon emerged from one hole the size of a pin-head, probably made by the first restless spiderling The emerging young of two cocoons were counted; one gave forth 101, and the other 92 spiderlings. The young at emerging do not resemble the mother, whose color is black and red, but they are all of a medium shade of brown. While the young do not spin nests of any certain form, they do spin webs of crisscross threads to which they cling. Fig. 1 shows a young spider (enlarged four times) clinging to these strands. In the glass cage in which they were kept, they almost always rested with the ventral surface of the body upwards, and with four or more legs holding on to the strands of criss-cross silk, as figured above.

While one seldom sees a nest of definite contour when one finds these adult spiders under stones, here confined in a large glass box (an unused aquarium), this spider made a large hollow

1. dentified by Mr. J. H. Emerton. 
Psyche, I924.

Vol. 3i, Plate VIII.
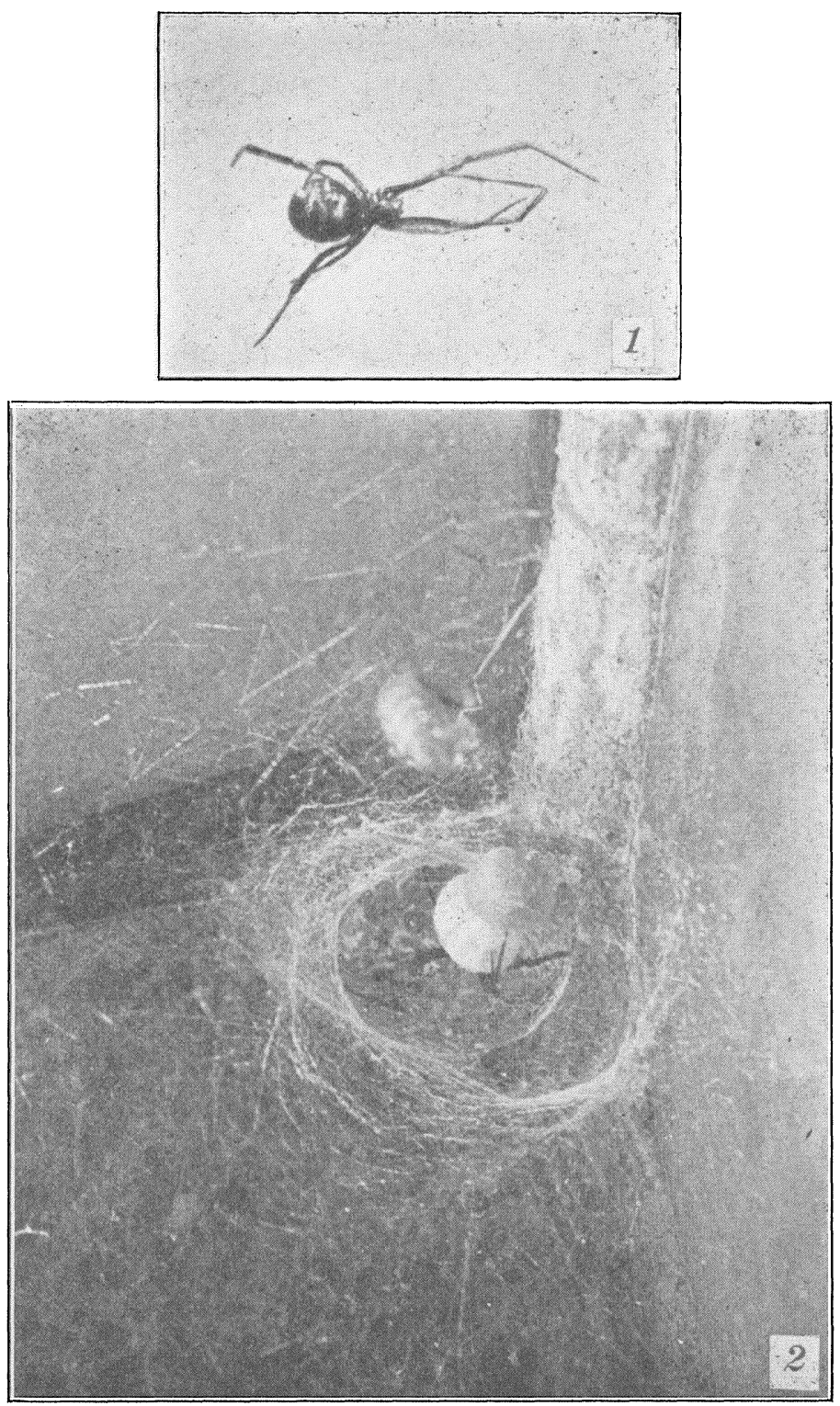

RaU-Life History of LAtrodectus. 
nest in which she spent all of her time except when prowling. Here too she made the cocoons, and here they reposed until such a time as the mother chose to kick them out. Fig. 2. shows the nest, natural size, with two coccons, and the mother clinging to the lower one; just above is the larva of a mud-wasp which I dropped there for food. The spider was fed wasp larvæ of various species, white grub worms and grasshopper nymphs in this way, by dropping them on the web. The spider would always carry these morsels to the bottom of her cup-like den and spin a web around the food. The manoeuvers were always carried on at night, however. The young were less timid, and would feed upon the wasp larva at various times during the day. This was done by merely standing upon it and sucking out its juices. There was no evidence of the very young spiders covering the prey with web. The mother spider occasionally fetches the prey from some little distance and carries it into the nest. I once placed the quiescent prepupa of the mud-dauber on the floor of the cage three inches away; during the night she removed this to her nest. This shows not only that she can move loads as large as herself over and through her webby entanglements, but also that her prey need not be active to attract her attention.

The spider kept the nest very tidy, and carried out all the dried remains of her food that had accumulated. She did not do this every day, but occasionally when the accumulation of rubbish became conspicuous she turned in for the general housecleaning. I once arrived in time to see the latter part of one of these affairs at $6 \mathrm{a} . \mathrm{m}$. This activity is also usually a night affair, but this time she did not finish until after day-break. Just as I arrived, she took up her last fragment, a dried grasshopper nymph, from the bottom of her lair, carried it by a circuitous route up to the rim of the hollow and cast it overboard where it dropped to the floor. She carried it in a queer fashion; with one hind leg she held it close to the tip of her abdomen while she slowly picked her way among the criss-cross threads of her web, until she reached a point from where it could be dropped below. All of the debris had been carried out during the night, and most 
of it had been carried some distance away. Most of the rubbish lay scattered at a distance of from eight to fifteen inches from the nest.

Her actions in regard to cleanliness appealed to me as commendable until I discovered that in her zeal she had also carried out and thrown away her own cocoon which she had just made; I wondered if she was not "throwing out the baby with the bath." Such a mental lapse or miscarriage of instinct caught my attention at once, and I watched for developments. But during the next few days, her behavior exhibited nothing short of maternal solicitude. As related above, in her early morning house-cleaning, she carried out the cocoon to a distance of eight inches, where it lay apparently discarded. The second morning thereafter I found the nest clean and the debris still scattered where she had dropped it. At 8 a. $\mathrm{m}$. I dropped into the crisscross webs above her den two wasp larvæ and a horse-fly, to tempt her appetite. At 9 p. m. the same day, I found the food items just where I had placed them, but to my astonishment, the cocoon that had lain on the floor eight inches away was now in the web, about two inches above her hollow nest, and the mother was clinging tenaceously to it. I promptly withdrew to avoid alarming her. My interpretation was that she was carrying the cocoon back to her den; an hour later when I again switched on the light, I found the cocoon nicely at rest on the bottom of the nest, and the mother clinging (I wish I dared say affectionately) to it. Her memory of her lost cocoon never failed her during the period of two and one-half days.

Quite likely the instinct-monger will interpret this behavior as a matter of accident; he will say that instinctively the spider carries food to the nest, and merely grabbed the cocoon in error. But I repeat that on top of the web were still entangled, three choice pieces of food that had remained untouched since morning, but she did not drag these nearby articles of food into her nest, but went afar and brought in the cocoon which she, in the heat of house-cleaning excitment, had discarded. Furthermore, let anyone who doubts the existence of maternal instinct here look at the picture and see the 
mother with all her legs entwined about this little ball, and ask him if he can imagine a spider clasping a food morsel in loving embrace for long hours at a time in this fashion; then he will know whether or not this mother herself knew the difference. $\mathrm{He}$ will agree with me that in the field of instincts, going in quest of food and taking care of the young arouse two distinct and remote responses. I therefore maintain that, with certain maternal instincts as a foundation, this mother spider, by the aid of associated memory, modified or enlarged certain inherent capacities to gain certain ends, although I doubt if she would have been able to recognize her own cocoon among others.

During the entire next day, whenever I visited the cage, this mother was clinging to her egg-case, and up to the last visit the food had not been removed from the webs where I had placed it. At dawn of the next day (July 30), I observed that the wasp larva was moved nearer to the den and was much reduced in size, and so shrivelled that I felt sure that the spider had drained its body juices during the night. Strange to relate, the cocoon was carried out again during the night, taken from the center of the hollow cup and hung in the webs an inch above the nest. The Spider seemed, however, to be almost playing with the egg-cise, for at 10 o'clock the same night when I paid her a visit, it was again back in the hollow of her nest. On August 1, when it was next observed, the cocoon was again out on the open web, two inches above the nest; the next day it was still in the same position. On August 4, the fourth egg-case had been made; the mother tightly clung to this in the hollow of her nest, while the one referred to previously had not been moved.

The third cocoon, the one left outside the den, gave forth 92 young on August 13, after a period of incubation of 32 days. During the night this egg-case had once more been carried away and dropped several inches away from the web, but I have no way of knowing whether this was done before or after the hatching occured. An actual moult occurs in the young spiders before they emerge, for on openirg a cocoon, one finds in addition to the empty egy shells the tiny shedding skins of the spiderlings. 
The fifth and last egg-case was made on August 15. Just before the event, the opening of the hollow nest had been extended upward for about an inch. This mother died on August 25 , ten days after completing her egg-case.

A second spider was taken on August 9, and died on September 20. Only fragmentary notes were made on this one. During this period she deposited four egg-cases, and all were found in a row in the corner of her cage among a tangled mass of threads that she made. While she had ample space, she made no elaborate or shapely nest as did the first.

This species is regarded as highly venomous, as are other species of this genus, and instances of fatalities are recorded by Warburton (Cambridge Natural History), Comstock (Spider Book), and Riley and Johannsen (Handbook of Medical Entomology). While the fact of its fatality to man is still in controversy, however, certain experiments carried on with mammals, 1 such as cats, dogs and guinea-pigs, show conclusively that this spider as well as others of the genus Latrodectus possesses a poison which paralyzes the heart and central nervous system.

${ }^{1}$ Handbook of Medical Entomology, p. 16. 1915. 

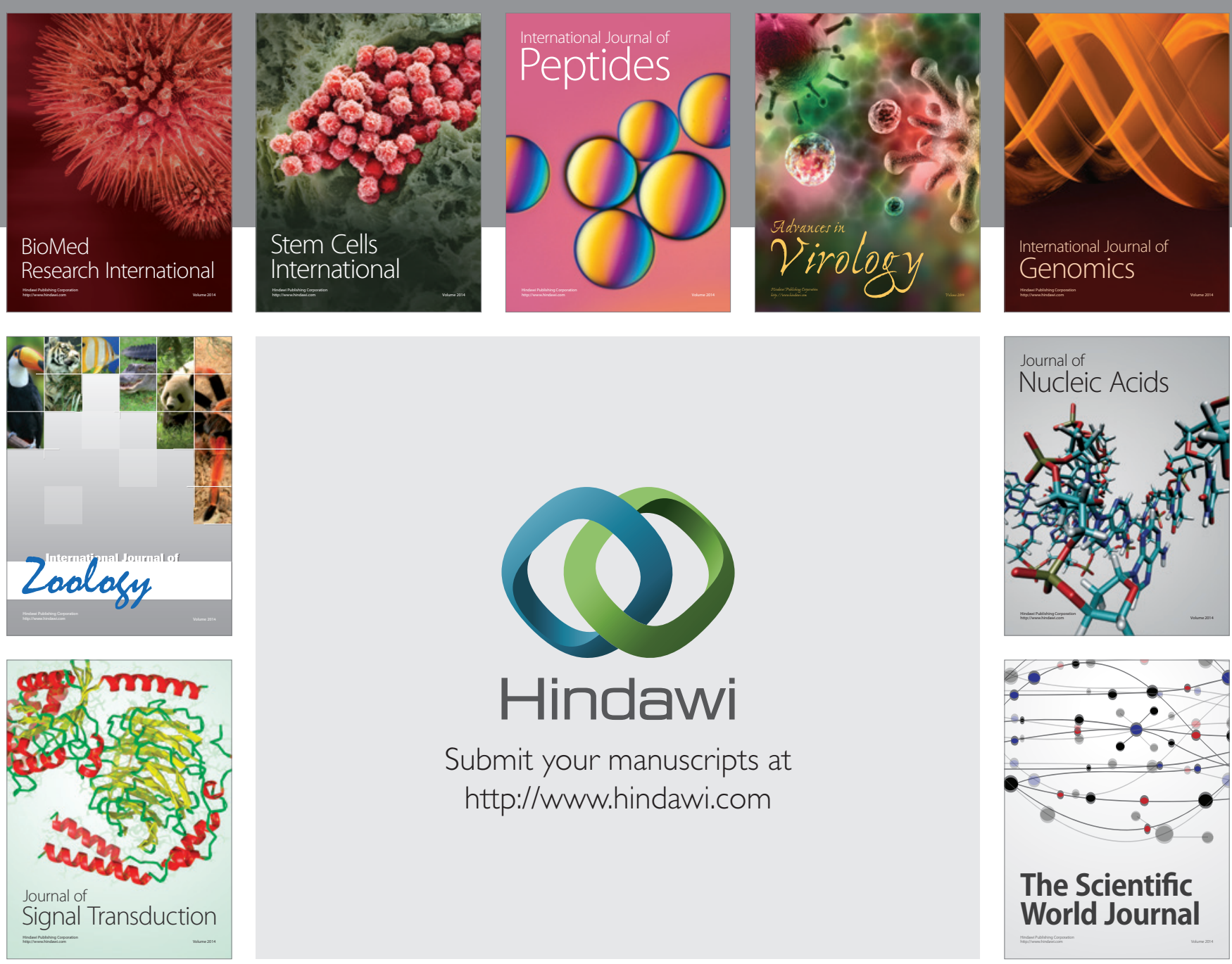

Submit your manuscripts at

http://www.hindawi.com
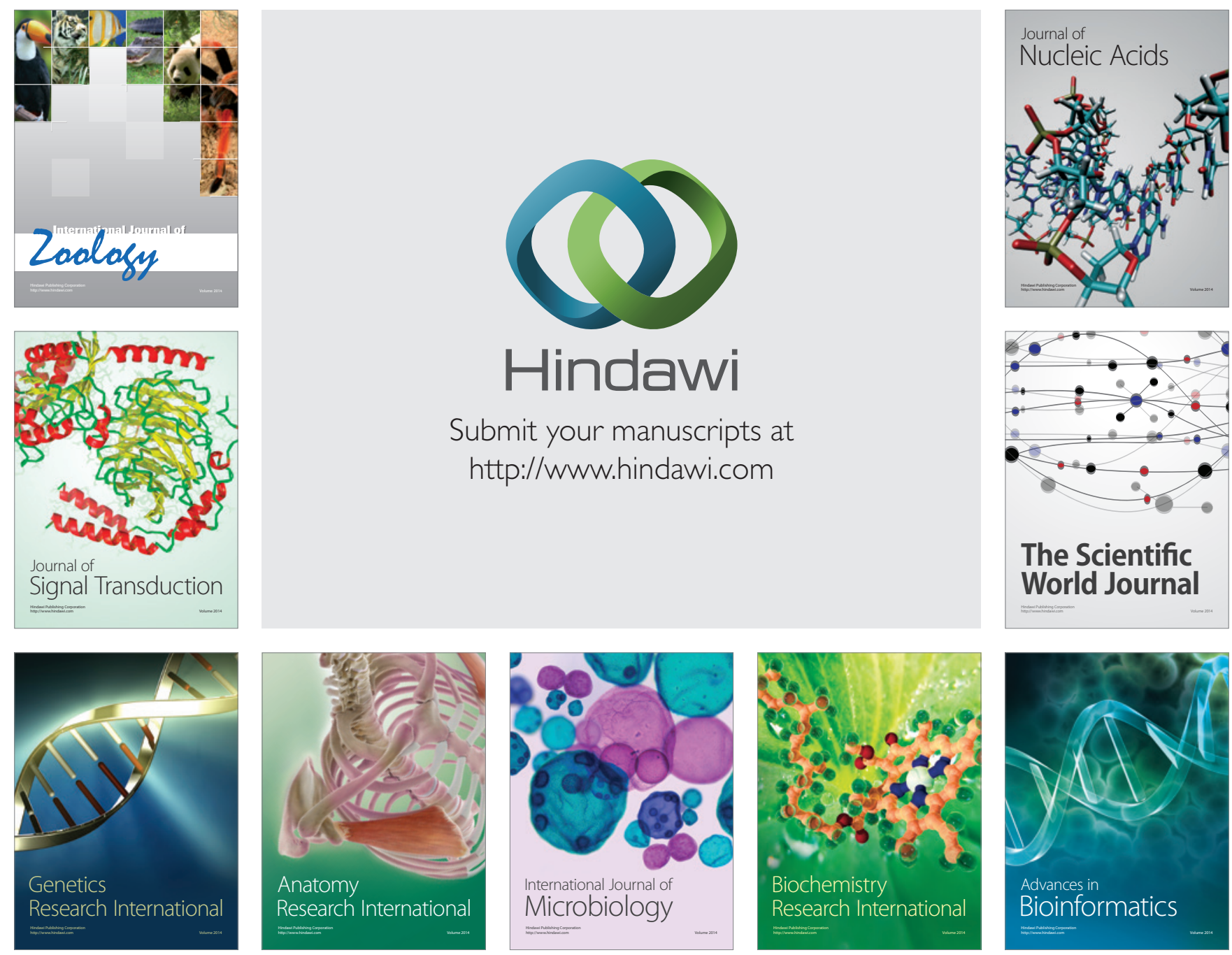

The Scientific World Journal
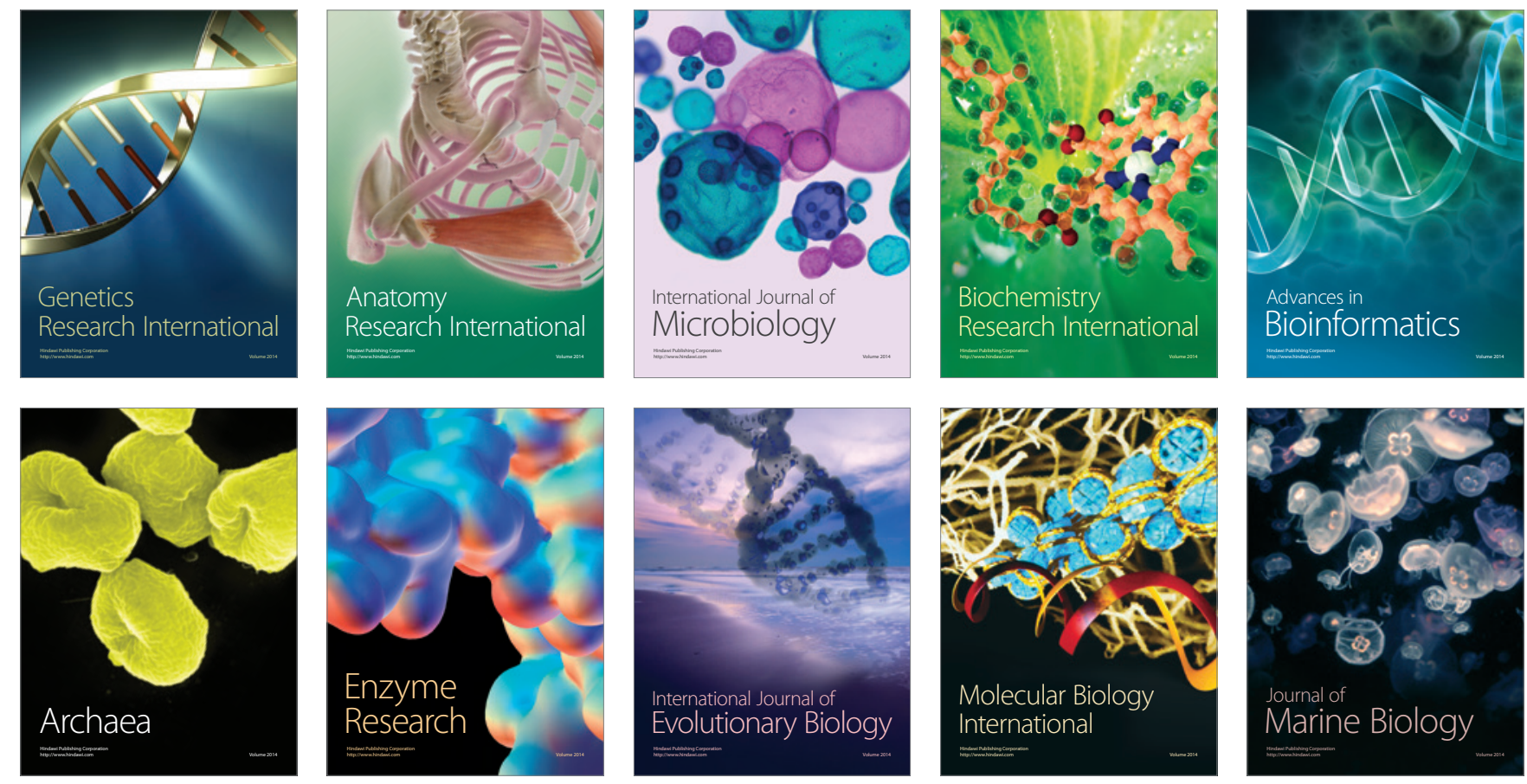